\title{
Incidência de Fungos Dos Gêneros Aspergillus e Penicillium Isolados de Especiarias
}

\author{
Gislaine Oliveira (I), Fabiana Reinis Franca Passamani (I), \\ Nathasha De Asevedo Lira (I), Theo De Rijk (II), Ed Boers (II), \\ Elaine Andrade Paula (I), Luís Roberto Batista (I) \\ (I) UFLA - UNIVERSIDADE FEDERAL DE LAVRAS (CAMPUS DA UFLA, CEP 37200-000, \\ CAIXAPOSTA 3037), (II) RIKILT - RIKILT - INSTITUTE OF FOOD SAFETY (Akkermaalsbos 2 \\ 6708WB WAGENINGEN)
}

\section{Resumo}

As exigências no controle de qualidade e nas condições higiênico-sanitárias dos alimentos são fundamentais e estão se tornando cada vez mais rigorosas, principalmente para os produtos destinados à alimentação humana. Especiarias estão propícias à contaminação por fungos filamentosos, aumentando o risco da ingestão de micotoxinas por parte da população, ameaçando a saúde pública, devido ao consumo regular. Este estudo teve como objetivo identificar e avaliar a incidência de fungos dos gêneros Aspergillus e Penicillium isolados de especiarias. Foram analisadas 8 amostras, sendo: 2 amostras de pimenta do reino branca, 2 amostras de noz-moscada, 2 amostras de páprica e 2 amostras de cúrcuma. Os fungos foram isolados através da técnica de espalhamento superficial a partir de diluições seriadas (10-1 a 10-3) em meio Dicloran Rosa de Bengala Cloranfenicol (DRBC) e Dichloran Glycerol Agar Base (DG18) por 7 dias a $25^{\circ} \mathrm{C}$. Após o período de incubação, os isolados foram purificados em meio (MA) Malte Agar a $25^{\circ} \mathrm{C}$ por 7 dias. As culturas puras foram transferidas para meio (CYA) Czapeck Yeast Agar a $25^{\circ} \mathrm{C}$ e $37^{\circ} \mathrm{C}$ e MEA (Agar Extract Malt) a $25^{\circ} \mathrm{C}$ por 7 dias. A identificação dos fungos foi realizada com o auxilio de manuais de identificação. As amostras de nozmoscada apresentaram os maiores níveis de contaminação. Foram isoladas e identificadas 133 espécies do gênero Aspergillus> sendo: 3 A. oryzae, 2 A. sydowi, 3 A. versicolor, 4 A. niveus, 82 A. tubingensis, 2 A. foetidus, 
13 A. niger, 7 Aspergillus sp., 13 A. flavus, 1 A. auricomus, 2 A. fumigatus, $1 \mathrm{~A}$. sojae, e 48 espécies do gênero Penicillium sendo: $8 \mathrm{P}$. fellutanum, $1 \mathrm{P}$ decumbens, $2 \mathrm{P}$. implicatum, $10 \mathrm{P}$. citrinum, $2 \mathrm{P}$. brevicompactum, 1 P. minioluteum, 12 P. verruculosum, 4 P. janthinellum, 7 P. paxilli, 1 P. oxalicum. Das espécies encontradas 7 são potencialmente toxigênicas, indicando um risco em potencial. O conhecimento de espécies toxigênicas é essencial para adoção de medidas de controle e garantia de um produto seguro.

Palavras-Chave: MICOTOXINAS, FUNGOS TOXIGÊNICOS, SEGURANÇA DE ALIMENTOS

Agência de Fomento: FAPEMIG, CNPq 